\title{
'Baby Cream', a High Yielding, Early Maturity, Cream-type Southernpea with a Compact Plant Habit
}

\section{Richard L. Fery}

U. S. Department of Agriculture, Agricultural Research Service, U.S. Vegetable Laboratory, 2700 Savannah Highway, Charleston, SC 29414-5334

Additional index words. Vigna unguiculata, cowpea, vegetable breeding

'Baby Cream' is a new southernpea [Vigna unguiculata (L.) Walp.] released by the U.S. Dept. of Agriculture, Agricultural Research Service. 'Baby Cream' is a cream-type southernpea that produces excellent yields of small, delicate peas. The new cultivar is adapted for production throughout the southeastern United States, where it can be expected to produce excellent yields of high quality cream-type peas. Cream-type southernpea cultivars have long been popular with home gardeners in the southern United States because they produce peas that are succulent and have a much milder, less starchy flavor and a better appearance than the blackeye or crowder types. Cream-type peas have little or no eye, and the liquor of the cooked product is light.

\section{Origin}

'Baby Cream' was developed over a 16-year period using a pedigree breeding procedure that included a single cross and repeated single-plant selections. The cross involved 'White Acre' and the breeding line US-432. 'White Acre' is a leading cream-type commercial cultivar; it is late maturing and has a large bush habit. US-432 was released by the USDA-ARS in 1988 (Fery and Dukes, 1990); it is early maturing, has a small, upright bushy habit, and produces cream-type peas. Following the cross, intense selection pressure was applied in the $F_{2}$ through $F_{8}$ generations for earliness, small plant habit, and 'White Acre' seed characteristics. 'Baby Cream' originated as the bulk of an $\mathrm{F}_{8}$ field population grown in 1996.

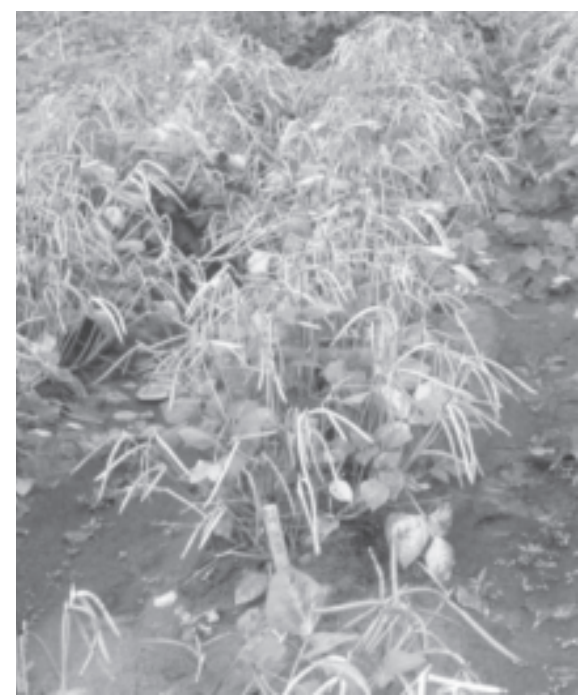

Fig. 1. Space-planted plot (three-plant hills spaced $30 \mathrm{~cm}$ apart; rows $102 \mathrm{~cm}$ apart) of 'Baby Cream' southernpea planted at the USDA-ARS U.S. Vegetable Laboratory research farm, Charleston, S.C.

Received for publication 10 Dec. 2005. Accepted for publication 4 Mar. 2006. The technical assistance of Floyd P. Maguire is gratefully acknowledged.

\section{Description}

'Baby Cream' has a compact, erect plant habit (Fig. 1). The new cultivar produces dry pods at Charleston, S.C., in 63 to $74 \mathrm{~d}$, which is 7 to $14 \mathrm{~d}$ earlier than 'White Acre'. The new cultivar is more resistant to lodging than many cream-type cultivars. The leaf color is an intermediate green; the leaf surface is smooth and glossy. There is no purple pigmentation on the stems, branches, petioles, or peduncles. Flower color is white; the back of the standard is yellow. Pods are borne in a bunched fashion above the foliage. Immature pods are attached to the peduncles at a $90^{\circ}$ angle; dry pods are attached in a pendant manner. Each peduncle typically produces two pods, but an occasional peduncle produces three or four pods.

Typical immature ‘Baby Cream'pods have a dark green color and do not exhibit any red or purple pigmentation. A typical fresh-shell stage pod is yellow in color, $15 \mathrm{~cm}$ long, slightly curved, exhibits only slight constrictions between peas, and contains 13 peas. There is a tendency for some reddish shading on the pod walls and a reddish color in the top vein as the fresh-stage pods dry. Dry pods exhibit a dark straw color with a slight reddish shading and some reddish color in the top vein. Fresh peas exhibit a primary cream color (similar to 'White Acre'), have a kidney shape, and weigh about $18 \mathrm{~g}$ per 100 peas. Dry peas have a smooth seedcoat.

The results of 5 years $(1999,2001-04)$ of replicated field testing at Charleston (Table 1) indicate that the yield potential of 'Baby Cream' is similar to that of 'Green Pixie'(Fery, 2000). 'Baby Cream'was tested as US-1031 throughout the southern United States for four years (2000-2003) as an entry in the Regional Southernpea Cooperative Trials. During the 4 years of testing in these trials (total of 27 tests in six states), the yield of 'Baby Cream' averaged $103 \%$ of the yield of the cream-type control ('Early Acre'). Canned samples of 'Baby Cream' peas scored well in quality evaluation tests conducted in 2000, 2001, 2002, and 2003 at the University of Arkansas (T. Morelock and J. Goff, unpublished data). The average processed grade of canned samples (average of scores over four years for color of peas, color of liquor, wholeness, texture, flavor, and general appearance: $1=$ poorest, $10=$ best; unacceptable score $<6$ ) was 8.11 . The results of many field tests indicate that 'Baby Cream' does not have unusual susceptibility to any major southernpea disease or insect pest.

'Baby Cream' is recommended for trial by both market gardeners and home gardeners for the production of fresh-shell, cream-type peas. It is also recommended for trial by commercial food processors as a replacement for 'White Acre'. 'Baby Cream' is much earlier and much less bushy than 'White Acre'; it should be more suitable for use in modern, high plant density cropping systems.

\section{Availability}

Breeder's seed of 'Baby Cream' has been released to seed producers. Small trial samples of breeder's seed are available from the author for distribution to all interested research personnel. Genetic material of this release will be deposited in the National Plant Germplasm System where it will be available for research purposes, including the development and commercialization of new cultivars. It is requested that appropriate recognition of source be given when this germplasm contributes to research or development of a new breeding line or cultivar.

\section{Literature Cited}

Fery, R.L. 2000. 'Green Pixie', a small-seeded, green cotyledon, cream-type southernpea. HortScience 35:954-955.

Fery, R.L. and P.D. Dukes. 1990. Registration of US-432 cowpea (southernpea) germplasm. Crop Sci. 30:428.

Table 1. Number of days to harvest, weight per 100 dry peas, and dry pea yield for 'Baby Cream' and 'Green Pixie' southernpeas grown in spring trials, Charleston, S.C., 1999-2004.

\begin{tabular}{|c|c|c|c|}
\hline Cultivar & $\begin{array}{l}\text { Days to } \\
\text { harvest } \\
\text { (no.) }\end{array}$ & $\begin{array}{c}\mathrm{Wt} / 100 \\
\text { dry peas } \\
(\mathrm{g})\end{array}$ & $\begin{array}{c}\text { Dry pea } \\
\text { yield } \\
\left(\mathrm{kg} \cdot \mathrm{ha}^{-1}\right)\end{array}$ \\
\hline \multicolumn{4}{|l|}{ Trial I, 1999} \\
\hline Baby Cream & $72.0 \mathrm{a}^{\mathrm{y}}$ & $8.5 \mathrm{a}$ & $1,026 \mathrm{a}$ \\
\hline Green Pixie & $72.0 \mathrm{a}$ & $8.0 \mathrm{a}$ & $984 \mathrm{a}$ \\
\hline \multicolumn{4}{|l|}{ Trial II, 2001} \\
\hline Baby Cream & $67.5 \mathrm{~b}$ & $6.7 \mathrm{~b}$ & $531 \mathrm{a}$ \\
\hline Green Pixie & $69.6 \mathrm{a}$ & $7.2 \mathrm{a}$ & $615 \mathrm{a}$ \\
\hline \multicolumn{4}{|l|}{ Trial III, 2002} \\
\hline Baby Cream & $69.7 \mathrm{a}$ & $9.8 \mathrm{a}$ & $1,055 \mathrm{a}$ \\
\hline Green Pixie & $72.0 \mathrm{a}$ & $9.7 \mathrm{a}$ & $893 \mathrm{a}$ \\
\hline \multicolumn{4}{|l|}{ Trial IV, 2003} \\
\hline Baby Cream & $74.0 \mathrm{a}$ & $7.5 \mathrm{a}$ & $752 \mathrm{~b}$ \\
\hline Green Pixie & $75.0 \mathrm{a}$ & $7.4 \mathrm{a}$ & $1,044 \mathrm{a}$ \\
\hline \multicolumn{4}{|l|}{ Trial V, 2004} \\
\hline Baby Cream & $62.8 \mathrm{~b}$ & $7.4 \mathrm{a}$ & $641 \mathrm{a}$ \\
\hline Green Pixie & $66.7 \mathrm{a}$ & $7.4 \mathrm{a}$ & $758 \mathrm{a}$ \\
\hline \multicolumn{4}{|c|}{ Combined analysis of all trials } \\
\hline Baby Cream & $68.8 \mathrm{~b}^{\mathrm{NS}}$ & $8.0 \mathrm{a}^{\mathrm{NS}}$ & $772 \mathrm{a}^{*}$ \\
\hline Green Pixie & $70.9 \mathrm{a}$ & $7.9 \mathrm{a}$ & $822 \mathrm{a}$ \\
\hline
\end{tabular}

${ }^{2}$ Spring 1999, 2001, 2002, 2003, and 2004 trials planted on 2 June, 5 June, 4 June, 12 June, and 23 June, respectively. Experimental design of each trial was a randomized complete block with 4 replications (1999), 6 replications $(2003,2004)$, or 10 replications $(2001,2002)$.

${ }^{y}$ Mean separation within columns and trials by Student-Newman-Keuls multiple range test, $P \leq 0.05$.

NS,"Nonsignificant or significant interaction between cultivar and trial at $P \leq 0.05$, respectively. 